\title{
Structure analysis of proteins, peptides and metal complexes by vibrational circular dichroism
}

\author{
Miklós Hollósi, ${ }^{a *}$ Elemér Vass, ${ }^{a}$ Gábor Szilvágyi, ${ }^{a}$ Andreja Jakas, ${ }^{\mathrm{b}}$ Ilona Laczkó ${ }^{\mathrm{c}}$ \\ ${ }^{a}$ Institute of Chemistry, Eötvös Loránd University, POB 32, H-1518 Budapest, Hungary \\ ${ }^{b}$ Department of Organic Chemistry and Biochemistry, Ruđer Bošković Institute, POB 180, 10002 \\ Zagreb, Croatia \\ ${ }^{c}$ Institute of Biophysics, Biological Research Center, POB 521, 6701 Szeged, Hungary \\ E-mail: hollosi@chem.elte.hu
}

\section{Dedicated to Professor Ferenc Fülöp on the occasion of his $60^{\text {th }}$ birthday}

\begin{abstract}
There are two principal forms of vibrational optical activity (VOA), an IR form referred to as vibrational circular dichroism (VCD) and Raman form known as Raman optical activity (ROA). This paper reports examples of the application of VCD spectroscopy for the determination of the absolute configuration and conformation of chiral molecules, e.g. cyclic $\beta$-lactams. VCD spectroscopy can be applied for the characterization of the conformation of proteins and peptides in solution. VCD based conformational analysis of cyclic peptides is discussed. Examples are the cyclic hexapeptide cyclo $\left(\mathrm{Pro}_{2}-\mathrm{Gly}-\mathrm{Pro}_{2}\right.$-Gly) and cyclic peptides comprising $\beta$-homoamino acids (trans-2-aminocyclopentane or trans-2-aminocyclohexane carboxylic acid). Structure analysis by VCD of opiate peptides, glycopeptides, peptidomimetics and chiral transition metal complexes are also discussed.
\end{abstract}

Keywords: Vibrational circular dichroism (VCD); determination of absolute configuration; characterization of protein conformation; structure analysis of cyclic peptides; VCD of glycopeptides and chiral transition metal complexes

\section{Introduction}

Vibrational optical activity (VOA) is due to the differential response of a molecule to leftcircularly polarized (LCP) versus right-circularly polarized (RCP) radiation during a vibrational transition. There are two principal forms of VOA, an IR form referred to as vibrational circular dichroism (VCD) and a Raman form known as Raman optical activity (ROA). Both VCD and ROA are very sensitive to the stereochemical features of chiral molecules, and they have similar differences and advantages to their parent spectroscopies, IR absorption and Raman scattering. ${ }^{1}$ 
The availability of commercial instrumentation for VCD and ab initio molecular orbital software for VCD intensity calculation in Gaussian 98 (and newer versions) from Gaussian Inc. have hastened the advance of VCD for widespread application in chemistry and biochemistry.

Perhaps the simplest application of VCD spectroscopy is the determination of the optical purity of a sample of a chiral molecule. The most important area of application of VCD to stereochemical analysis is the determination of absolute configuration in solution. ${ }^{2}$ VCD can also be used to monitor the conformation of a chiral molecule in various solution environments.

\section{Results and Discussion}

In our laboratory the first application of VCD spectroscopy combined with quantum chemical calculations at DFT level of theory was used for the determination of the absolute configuration and conformation of a series of cyclic $\beta$-lactams. ${ }^{3}$ A direct enzymatic method for the preparation of cyclic $\beta$-lactams and $\beta$-amino acids was recently developed involving the lipolase-catalyzed enantioselective hydrolysis of racemic $\beta$-lactams in an organic solvent. The VCD analysis indicated the homochirality of the studied lactams. As shown in Figure 1 there is a good agreement between the measured and computed VCD spectrum of one of the possible conformers of the $\beta$-lactam derivative of cis 2-amino-cyclopentanecarboxylic acid (1).

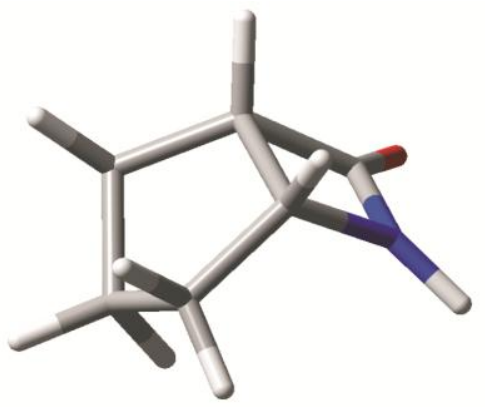

conformer 1a $>99.5 \%$

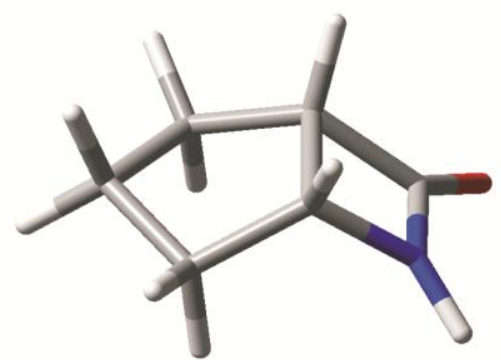

conformer $\mathbf{1 b}$

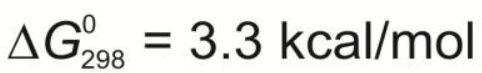

$<0.5 \%$

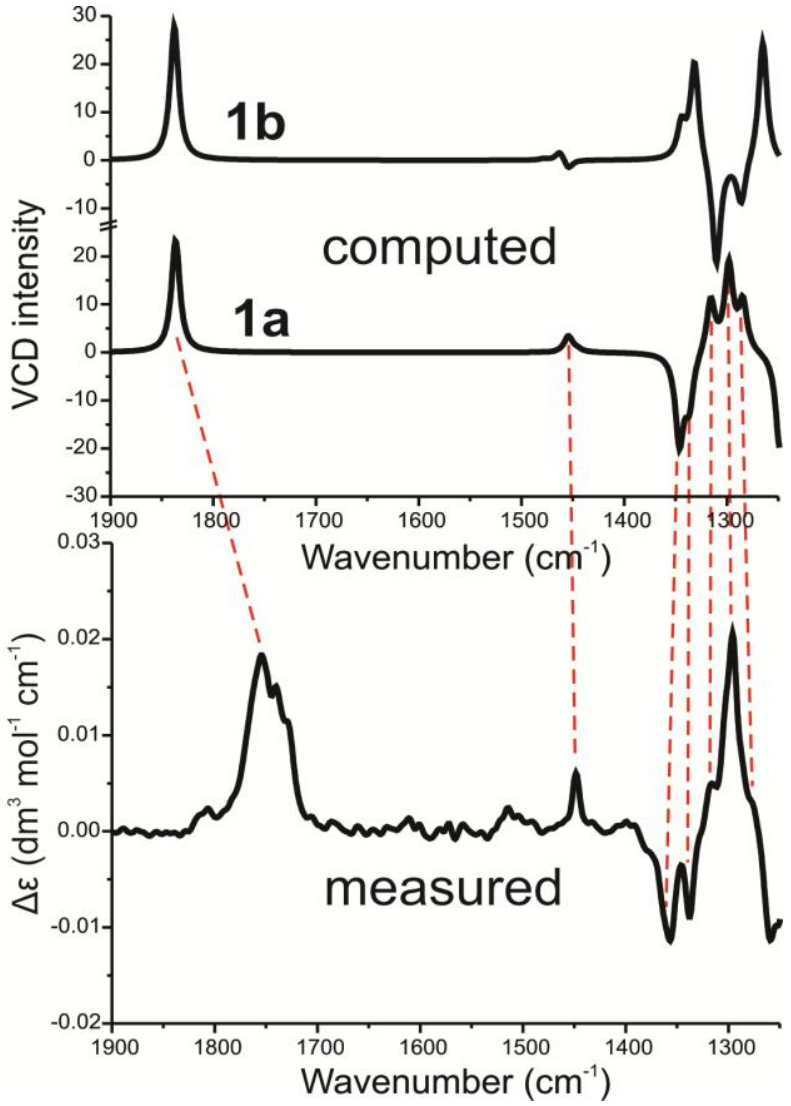

Figure 1. Measured VCD spectrum of $\beta$-lactam derivative 1 in comparison with the computed VCD spectra of the two possible conformers (1a and $\mathbf{1 b})$. 


\section{VCD spectroscopy of proteins}

The first attempts to measure VCD spectra of biopolymers dealt with synthetic $\alpha$-helical homopolypeptides. The amide I band (amide I' in $\mathrm{D}_{2} \mathrm{O}$ ) is the most characteristic and easiest way to monitor VCD spectrum of proteins. The characteristic feature of $\alpha$-helix VCD is a positive couplet with a more intense negative lobe and an additional weak negative band (Figure 2). The amide I' VCD spectrum for the antiparallel $\beta$-sheet shows two separated negative bands, while a negatively biased negative couplet for the unordered form. ${ }^{4}$ In oligo- and polypeptide examples, the $\beta$-sheet is almost always an antiparallel $\beta$-stranded conformation of low solubility. This aggregated form is most easily recognized by its characteristic, widely split amide I' band with a major, low-wavenumber feature at $\sim 1620-15 \mathrm{~cm}^{-1}$ and a weaker one at $\sim 1690 \mathrm{~cm}^{-1}$ (Figure 2, middle).

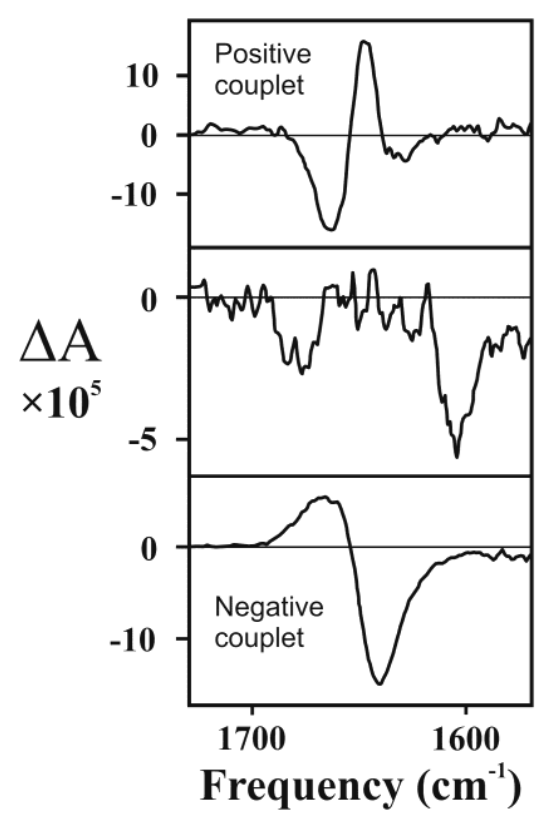

Figure 2. VCD spectra of the $\alpha$-helix (positive couplet), $\beta$-sheet and unordered conformation (negative couplet) of proteins.

$3_{10}$-Helices and $\beta$-bend ribbons in oligomers can also be characterized on the basis of magnitude as well as band shape of amide I', II and A bands. The amide I' VCD couplet of the $3_{10}$-helix has the same sign pattern (positive/negative) as that of the $\alpha$-helix, but the amide I' VCD of $3_{10}$ helix is much weaker than the amide II VCD, while the opposite is true for the $\alpha$ helix. VCD can also be used to characterize mixed $\alpha / 3_{10}$-helical conformations and $\beta$-bend ribbon structure. ${ }^{5}$

There are distinct differences between the amide II VCD for $\alpha$-helices (dominant negative) and that for $\beta$-sheet (negative couplet). Concerning the amide III region between $\sim 1350$ and 1250 $\mathrm{cm}^{-1}, \alpha$-helices have mostly positive while $\beta$-sheets negative VCD. 
VCD results support the early hypothesis based on ECD measurements that the unordered or random-coil form can best be viewed as a left-handed, extended helix, that is poly(proline) II or PPII conformation. ${ }^{6}$

To take advantage of the detailed information available from VCD, it has been developed a new predictive method of secondary structures (including $\alpha$-helix, $\beta$-sheet, turns and others), using statistical analysis of spectral data obtained from VCD, IR and ECD spectra. In ROA the vibrations of interest for conformational analysis of peptides and proteins are the backbone skeletal region $\left(1150-870 \mathrm{~cm}^{-1}\right)$, the amide III region extended to at least $1340 \mathrm{~cm}^{-1}$ and the amide I region. ${ }^{7}$ The ROA bands in the amide III region often dominate the overall spectrum.

\section{VCD spectroscopy of peptides}

VCD spectroscopy has today a broadscale application for the conformational analysis of cyclic peptides. ${ }^{8}$ The limited number of conformers in cyclic peptides is of great help in the theoretical calculation of VCD spectra.

Cyclic peptides containing four to six amino acid residues are good models of $\beta$-turns and related structures. They exhibit relatively distinct VCD features, suggesting that VCD is extremely sensitive to local structures and it can distinguish between various turn conformations. Indeed, unique spectra of type I and II $\beta$-turns in cyclic peptides have been reported by Diem and co-workers that differ from those of type III $\beta$-turns. ${ }^{9}$ Many cyclic models listed in Ref. 8 show a positive couplet about or above $\sim 1660 \mathrm{~cm}^{-1}$. This positive couplet was assigned to type II $\beta$ turns. $^{10}$

A recent theoretical paper by Keiderling and coworkers ${ }^{11}$ presents a systematic analysis of the expected amide I and II VCD band patterns associated with standard (type I-III) and mirrorimage (type I'-III') $\beta$-turn structures. Calculations were performed at BPW91/6-31G** level on Ac-Xxx-Yyy-NHMe type model peptides with different amino acids in the corner positions. They show that type I and III $\beta$-turns have very similar pattern (positive couplet in the amide I), making their discrimination quite difficult. One important conclusion is that in the case of type II turns, the key is not the amide I mode, but the amide II which tends to give opposite sign pattern, allowing the discrimination of type II $\beta$-turns from type I (or III) turns.

An example of applying VCD spectroscopy for cyclic peptides is the conformational analysis of the antamanide-analogue cyclic peptide $\operatorname{cyclo}\left(\mathrm{Pro}_{2}-\mathrm{Gly}-\mathrm{Pro}_{2}-\mathrm{Gly}\right)$ (2). The chemistry, cation binding capability and biological activity of the antitoxic cyclic decapeptide antamanide have been thoroughly studied by Wieland and coworkers. ${ }^{12}$ As a part of systematic investigations into the conformation of antamanide and its analogues, a series of cyclic peptides consisting of glycine and two pairs of L-proline have also been synthesized. As inferred from ${ }^{1} \mathrm{H}$ and ${ }^{13} \mathrm{C}$ NMR data 2, the first member of the series, preferentially adopts asymmetric solution conformations. ${ }^{13}$ In $\mathrm{CDCl}_{3} \mathbf{2}$ occurs in a single conformational state featuring a cis Pro-Pro peptide bond. In DMSO- $d_{6}$ the conformational equilibrium is dominated by another conformer (approx. 85\%) with cis $\mathrm{Gly}^{3}-\mathrm{Pro}^{4}$ cis $\mathrm{Pro}^{4}-\mathrm{Pro}^{5}$ geometry (Figure 3). Spectral data strongly suggest the presence of an unusual H-bonded $\beta$-turn with two Pro residues in consecutive corner positions in both conformers. The crystal structure of the trihydrate form of $\boldsymbol{2}$ has been 
determined from single-crystal X-ray diffraction data. In the crystal only the two-cis conformer is present. X-ray structure analysis confirmed its NMR-based conformational characteristics. ${ }^{14}$ The torsion angles of the $\beta$-turn were close to the Venkatachalam-values of a $\beta$-turn type I.

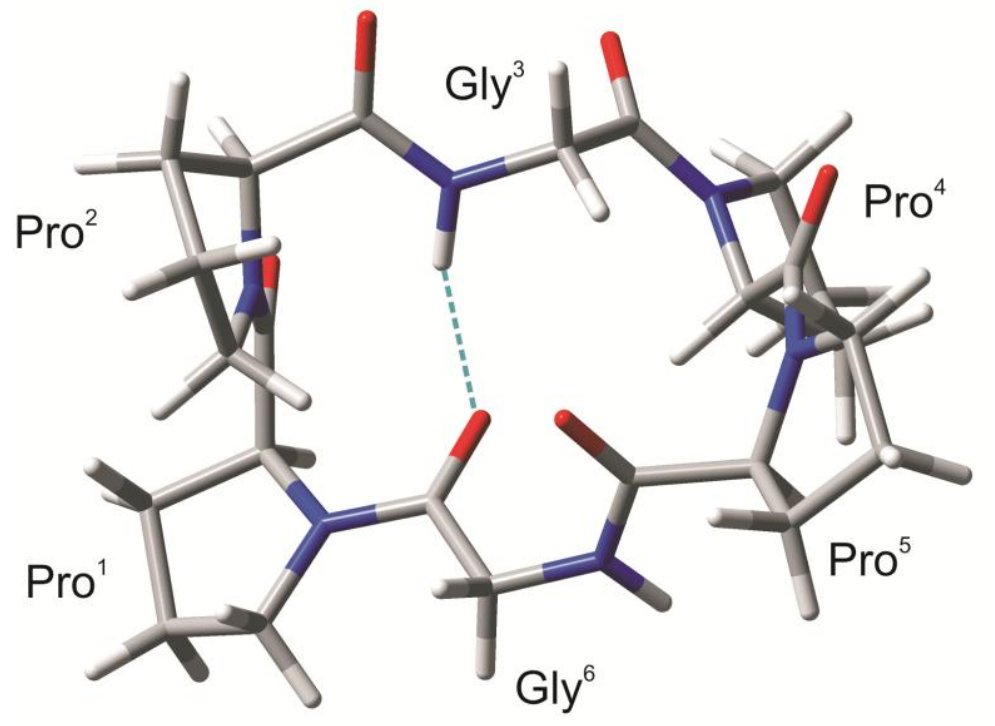

Figure 3. The dominant conformer of cyclo(Pro $\left.{ }_{2}-\mathrm{Gly}_{-} \mathrm{Pro}_{2}-\mathrm{Gly}\right)(2)$ in DMSO- $d_{6}(\sim 85 \%)$ with cis $\mathrm{Gly}^{3}$-Pro ${ }^{4}$ and cis $\mathrm{Pro}^{4}$-Pro ${ }^{5}$ peptide bonds and an unusual H-bonded $\beta$-turn between Gly ${ }^{6}$ and Gly.

This structure is also reinforced by a recent FTIR and VCD spectroscopic study on cyclo(Pro 2 -Gly-Pro 2 -Gly) (2) in DMSO-d $\mathrm{d}_{6}$ solution, which are in very good agreement with the calculated spectrum of the two-cis conformer at the B3LYP/6-31G* level of theory, using a polarizable continuum solvent model for DMSO (see Figure 4). The amide I region of the FTIR spectrum shows 3 partly overlapped bands (at 1648,1668 and $1689 \mathrm{~cm}^{-1}$ ) resulting from coupled amide I vibrational modes, out of which the lowest-wavenumber band has high contribution from the H-bond acceptor amide carbonyl of the $\beta$-turn structure. The amide II region is characterized by two overlapping bands, at 1537 and $1564 \mathrm{~cm}^{-1}$, respectively the latter being assigned to the $\mathrm{H}$ bond donor amide NH group of Gly. ${ }^{3}$ The VCD spectrum shows four amide I bands of alternating sign, appearing as two consecutive positive couplets, and a weak, negative amide II band. The two higher-wavenumber amide I VCD bands, at $1668 \mathrm{~cm}^{-1}$ and $1689 \mathrm{~cm}^{-1}$, are contributed from the amide I modes of the secondary amide groups of the two Pro-Gly peptide bonds. The positive couplet-like feature appearing at lower wavenumber, composed of a positive band at $1635 \mathrm{~cm}^{-1}$ and negative band at $1650 \mathrm{~cm}^{-1}$, is mostly due to vibrations of the amide groups of the amino acid residues forming the $\beta$-turn structure, the positive band being clearly assigned to the H-bond acceptor tertiary amide group of Gly. ${ }^{6}$ The sign of the bands is also in agreement with the predicted positive couplet for a type I $\beta$-turn structure. ${ }^{11}$ 

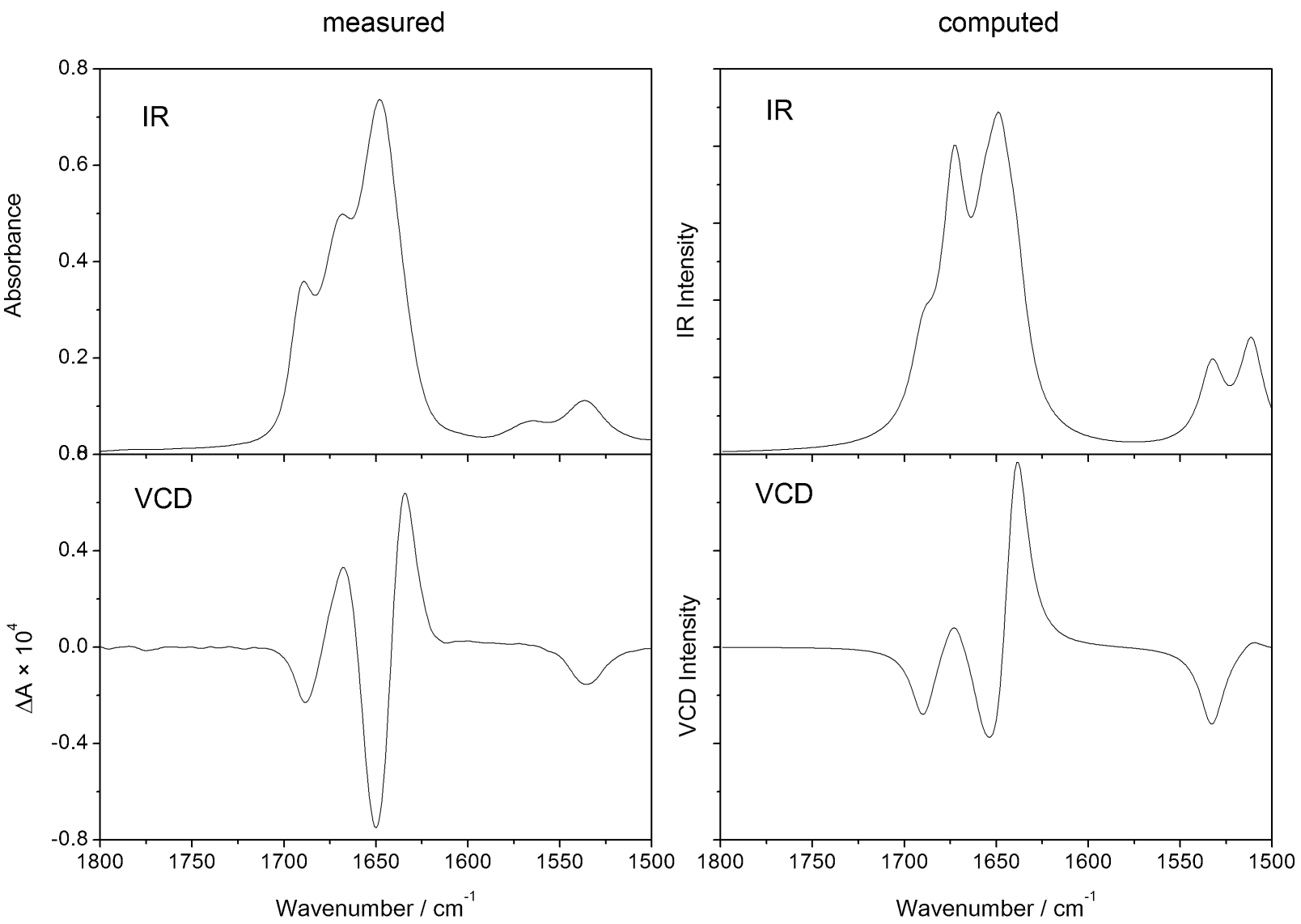

Figure 4. IR and VCD spectra of cyclo(Pro $\left.{ }_{2}-\mathrm{Gly}_{-} \mathrm{Pro}_{2}-\mathrm{Gly}\right)(2)$ in DMSO- $d_{6}$ (left) in comparison with the calculated spectra of the dominant conformer (right). The experimental spectra are in very good agreement with the calculated spectra of the two-cis conformer at the B3LYP/6-31G* level of theory using PCM solvent model for DMSO.

Cyclic penta- and hexapeptides comprising $\beta$-homoamino acids (trans-2-aminocyclopentane or trans-2-aminocyclohexane carboxylic acid) were also studied by $\mathrm{VCD}^{15}$. They showed similar VCD spectra which indicates that the conformation of the trans-derivatives are determined by the steric structure of the trans-2-aminocyclopentane or trans-2-aminocyclohexane carboxylic acids.

\section{VCD spectroscopy of peptide derivatives}

Opioid peptides are responsible for a variety of processes in organisms, the best characterized of which are analgesia, sedation, euphoria, respiratory depression and a peripherial action as an antidiarrheic. ${ }^{16}$ A very broad spectrum of biological activities rendered endogenous opioid peptides, Leu- and Met-enkephalin (Tyr-Gly-Gly-Phe-Leu/Met), ${ }^{17}$ as important targets with a good potential for further development as therapeutic agents.

The carbohydrate moieties of glycoproteins and glycopeptides are believed to have important roles in their biological activity. Comparative electronic circular dichroism and Fourier transform 
infrared (FTIR) spectroscopic properties of glycopeptides and glycopeptide derivatives in comparison with spectroscopic data obtained for the non-modified parent opioid peptides, Leuenkephalin and Leu-enkephalin amide have been reported earlier. ${ }^{18}$ It was found that carbohydrate moiety aids in the formation of a secondary structure of a peptide backbone, especially the $\beta$-turn, or stabilizes the peptide backbone conformation. ${ }^{19}$

The VCD spectra of Leu-enkephalin (3) and its imidazolidinone derivative (4) were measured in TFE (Figure 5). In the amide I spectral region the positive band at $1684 \mathrm{~cm}^{-1}$ can be assigned to solvated and buried amide carbonyls. The negative band at $1618 \mathrm{~cm}^{-1}$ is contributed by the ring vibration of Tyr. Apart from the negative band at $1583 \mathrm{~cm}^{-1}$ the region between $\sim 1570$ and $1500 \mathrm{~cm}^{-1}$ shows positive band(s) (amide II, asymmetric $\mathrm{COO}^{-}$stretching and $\mathrm{NH}_{3}{ }^{+}$ deformation bands). In the presence of $\mathrm{Ca}^{2+}$-ions at $\mathrm{r}_{\mathrm{Ca}}=0.5$ the sign of the bands in the 1700$1600 \mathrm{~cm}^{-1}$ region are opposite of those in the VCD spectrum of Leu-enkephaline. Except from one positive band at $1550 \mathrm{~cm}^{-1}$ all the bands in the $1600-1500 \mathrm{~cm}^{-1}$ region are negative (Figure 5). The spectral change caused by $\mathrm{Ca}^{2+}$-ions at $\mathrm{r}_{\mathrm{Ca}}=0.5$ is an indication of the binding of $\mathrm{Ca}^{2+}$ ions and the shift of the conformational equilibrium. However, it is almost impossible to predict the type and number of the participating conformers.

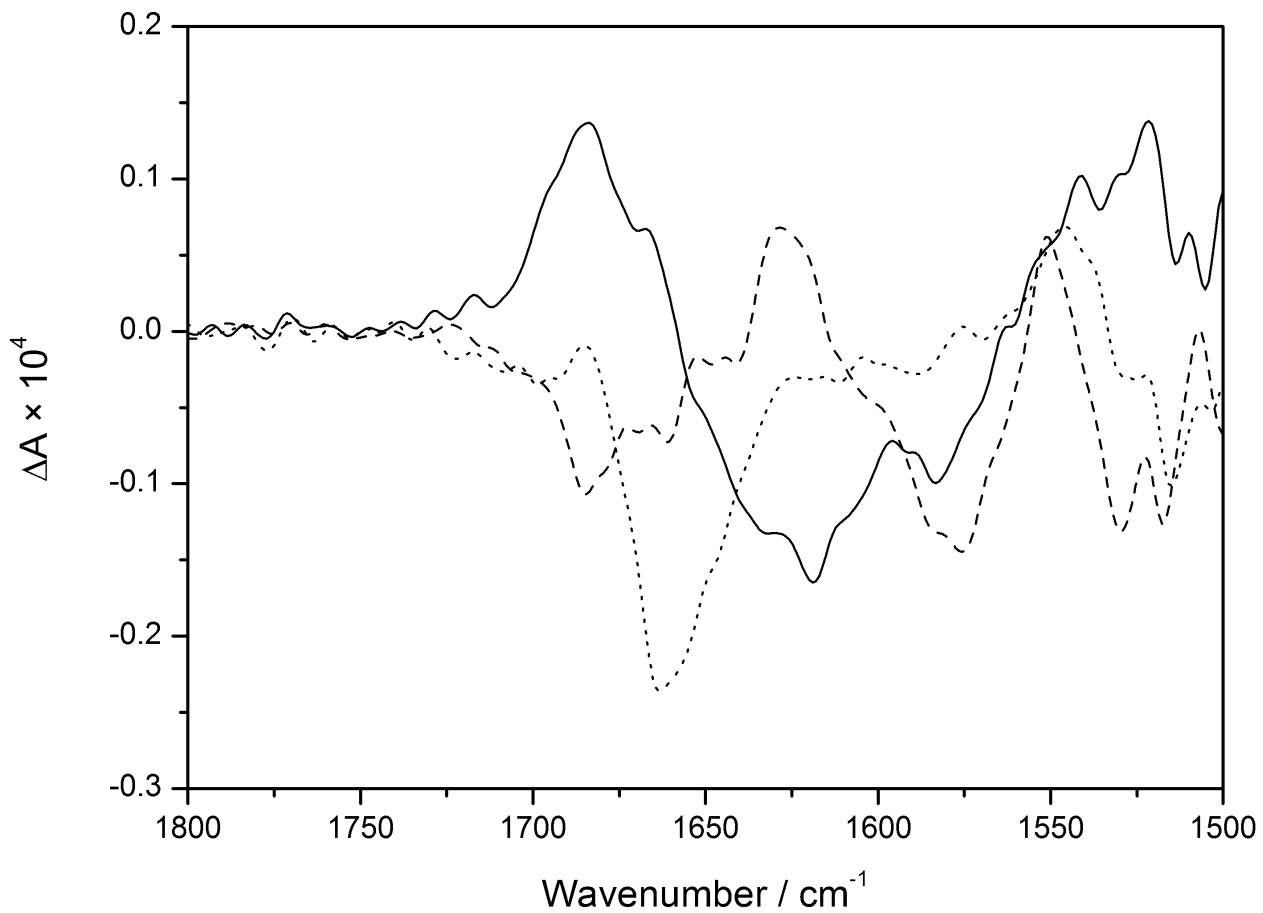

Figure 5. The VCD spectra of Leu-enkephalin (3) (solid line) and in presence of $\mathrm{Ca}^{2+}$ ions at $r_{c a}=0.5$ (dashed line), as well as the spectrum of the imidazolidinone derivative (4) (dotted line) recorded in TFE solution.

The VCD spectrum in TFE of the imidazolinone-derivative is dominated by an intense negative band at $1663 \mathrm{~cm}^{-1}$ with a lower wavenumber shoulder and a weak positive band at 1685 
$\mathrm{cm}^{-1}$. A positive and a negative band appear between 1550 and $1500 \mathrm{~cm}^{-1}$. This spectrum is compatible with the presence of unordered conformation and folded structures.

\section{VCD investigation of transition metal complexes}

The conformation of chiral dirhodium complexes was also studied by ECD and VCD spectroscopy. ${ }^{20}$ The ECD spectra of the complexes depend on temperature that indicates the conformational mobility of the chiral ligands. The agreement between the measured and calculated VCD spectra gave unique information on the steric structure of complexes $\mathrm{Rh}_{2}(\mathrm{O}$ Phe-Cbz $)_{1}(\mathrm{OAc})_{3}(5)$ or $\mathrm{Rh}_{2}(\mathrm{O}-\mathrm{Phe}-\mathrm{Ac})_{1}(\mathrm{OAc})_{3}(\mathbf{6})$. Calculations of the VCD spectra were performed at DFT level of theory using Gaussian 03. The population-weighted sums of the computed VCD spectra of the conformers are in excellent agreement with the experimental VCD spectra (Figure 6). The combination of the VCD and ECD spectroscopic methods led us to the structural characterization of the complexes. The lowest energy conformer of the $\mathrm{Rh}_{2}(\mathrm{O}-\mathrm{Phe}$ $\mathrm{Cbz})_{1}(\mathrm{OAc})_{3}$ complex is shown in Figure 6a. The phenyl ring of the urethane protecting group is situated in the vicinity of a $\mathrm{C}-\mathrm{H}$ hydrogen of the donor $\mathrm{MeCN}$ molecule. This suggests that it interacts with the $\pi$ electrons of the phenyl ring ( $\sigma-\pi$ interaction).
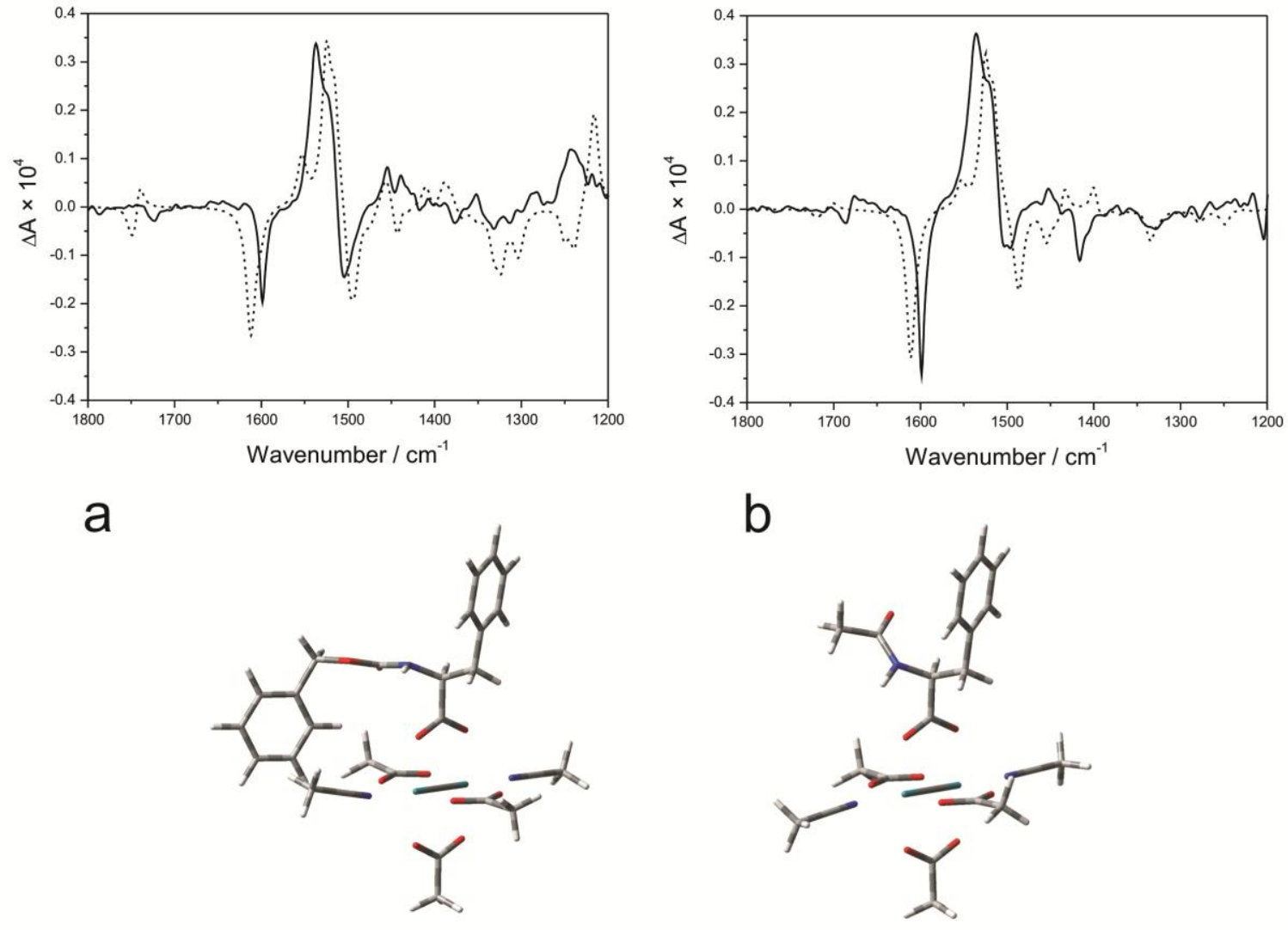

Figure 6. Experimental (solid line) and calculated (dotted line) VCD spectra in $\mathrm{CD}_{3} \mathrm{CN}$ as well as the lowest energy conformers of $\mathrm{Rh}_{2}(\mathrm{O}-\mathrm{Phe}-\mathrm{Cbz})_{1}(\mathrm{OAc})_{3}(\mathbf{a})$ and $\mathrm{Rh}_{2}(\mathrm{O}-\mathrm{Phe}-\mathrm{Ac})_{1}(\mathrm{OAc})_{3}(\mathbf{b})$. 


\section{Conclusion}

The examples described in this paper demonstrate the applicability of vibrational circular dichroism spectroscopy for the determination in solution of the absolute configuration of the chirality center(s) of chiral molecules and the characterization of the absolute conformation of proteins and peptides.

\section{Acknowledgement}

The VCD spectroscopic investigations were supported by the Hungarian Research Fund OTKA (grant K81175 to Miklós Hollósi).

\section{References}

1. Dukor, R. K.; Nafie, L. A. In Encyclopedia of Analytical Chemistry; Meyers, R. A. Ed., John Wiley \& Sons: Chiscester U.K., 2000, pp. 662-676.

2. Nafie, L. A.; Freedman, T. B. Enantiomer 1998, 3, 283.

3. Vass, E.; Hollósi, M.; Forró, E.; Fülöp, F. Chirality 2006, 18, 773.

4. Keiderling, T. A. In Circular Dichroism. Principles and Applications; Berova, N.; Nakanishi, K.; Woody, R. W. Eds., Wiley-VCH: New York, 2000; pp. 621-666.

5. Yoder, G.; Polese, A.; Silva, R. A. G. D.; Formaggio, F.; Crisma, M.; Broxterman, Q. B.; Kamphuis, J.; Toniolo, C.; Keiderling, T. A. J. Am. Chem. Soc. 1997, 119, 10278.

6. Dukor, R. K.; Keiderling, T. A. Biopolymers 1991, 31, 1747.

7. Barron, L. D.; Hecht, L.; Blanch, E. W. Bell, A. F. Progr. Biophys. Mol. Biol. 2000, 73, 1.

8. Vass, E.; Hollósi, M.; Besson, F.; Buchet, R. Chem. Rev. 2003, 103, 1917.

9. Wyssbrod, H. R.; Diem, M. Biopolymers 1992, 31, 1237.

10. Xie, P.; Zhou, Q.; Diem, M. J. Am. Chem. Soc. 1995, 117, 9502.

11. Kim, J.; Kapitán, J.; Lakhani, A.; Bouř, P.; Keiderling, T. A. Theor. Chem. Acc. 2008, 119, 81.

12. Wieland, Th.; Faulstich, H.; Burgermeister, W.; Otting, W.; Möhle, W.; Shemyakin, M. M.; Ovchinnikov, Yu. A.; Ivanov, V. T.; Malenkov, A. G. FEBS Lett. 1970, 9, 89.

13. Radics, L.; Hollósi, M. Tetrahedron Lett. 1980, 21 , 4531.

14. Czugler, M.; Sasvári, K.; Hollósi, M. J. Am. Chem. Soc. 1982, 104, 4465.

15. Vass, E.; Strijowski, U.; Wollschläger, K.; Mándity, I. M.; Szilvágyi, G.; Jewgiński, M.; Gaus, K.; Royo, S.; Majer, Z.; Sewald, N.; Hollósi, M. J Peptide Sci. 2010, 16, 613.

16. Olson, G.A.; Olson, R.D.; Kastin, A.J. Peptides 1997, 18, 1651.

17. Hughes, J.; Smith, T. W.; Kosterlitz, H. W.; Fothergill, L. A.; Morris, H. R. Nature 1975, $258,577$. 
18. Horvat, Š.; Jakas, A.; Vass, E.; Samu, J.; Hollósi, M. J. Chem Soc. Perkin Trans. 2 1997, 2 , 1523.

19. Vass, E.; Hollósi, M.; Kveder, M.; Kojić-Prodić, B.; Čudić, M.; Horvat, Š. Spectrochim. Acta Part A, 2000, 56, 2479.

20. Szilvágyi, G.; Majer, Z.; Vass, E.; Hollósi, M. Chirality 2011, 23, 294. 